\title{
Erratum to: Influence of Dimensional Effects on the Curie Temperature of by and Ho Thin Films
}

\author{
D. I. Devyaterikov ${ }^{a}$, V. V. Proglyado ${ }^{a}$, V. D. Zhaketov ${ }^{c}$, Yu. V. Nikitenko ${ }^{c}$, O. A. Kondrat'ev ${ }^{d}$, \\ E. M. Pashaev ${ }^{d}$, I. A. Subbotin ${ }^{d}$, V. I. Zverev ${ }^{e}$, E. A. Kravtsov ${ }^{a, b}, *$, and V. V. Ustinov ${ }^{a, b}$ \\ ${ }^{a}$ Mikheev Institute of Metal Physics, Ural Branch, Russian Academy of Sciences, Ekaterinburg, 620108 Russia \\ ${ }^{b}$ Ural Federal University n.a. the First President of Russia B.N. Yeltsin, Ekaterinburg, 620002 Russia \\ ${ }^{c}$ Joint Institute for Nuclear Research, Dubna, 141980 Russia \\ ${ }^{d}$ National Research Center Kurchatov Institute, Moscow, 123182 Russia \\ ${ }^{e}$ Lomonosov Moscow State University, Physical Department, Moscow, 119991 Russia \\ *e-mail kravtsov@imp.uran.ru \\ Received November 19, 2020; revised December 23, 2020; accepted January 4, 2021
}

DOI: $10.1134 / \mathrm{S} 0031918 X 21880013$

The article "Influence of Dimensional Effects on the Curie Temperature of by and Ho Thin Films", written by D. I. Devyaterikov, V. V. Proglyado, V. D. Zhaketov, Yu. V. Nikitenko, O. A. Kondrat'ev, E. M. Pashaev, I. A. Subbotin, V. I. Zverev, E. A. Kravtsov, and V. V. Ustinov, was originally published electronically in Springer-Link on 01 may 2021 without Open Access. After publication in volume 122, issue 5, pages 465-471 the authors decided to make the article an Open Access publication. Therefore, the copyright of the article has been changed to (C) The Author(s) 2021 and the article is forthwith distributed under the terms of a Creative Commons Attribution 4.0 International License (http://creativecommons.org/ licenses/by/4.0/, CC BY), which permits use, duplication, adaptation, distribution and reproduction of a work in any medium or format, as long as you cite the original author(s) and publication source, provide a link to the Creative Commons license, and indicate if changes were made.

The original article can be found online at https://doi.org/10.1134/S0031918X21050033 